\title{
Coaches' Attitudes Toward Campus Board Training in Adolescent Climbers in the United States
}

\author{
Christopher W. McMullen, MD; Brian J. Mugleston, MD, MEd; Lyndsey N. Booker, MD \\ Department of Rehabilitation Medicine, University of Washington School of Medicine, Seattle, Washington
}

\begin{abstract}
Introduction-Campus board training in adolescent climbers is controversial. Evidence, albeit limited, suggests this type of training may lead to the development of finger epiphyseal stress fractures. The purpose of the present study was to investigate coaches' attitudes toward campus board training in the United States.

Methods-Surveys were sent to 116 coaches at gyms across the United States with affiliated adolescent climbing teams. Outcomes collected included demographic information, training time, campus board use prevalence, coaches' attitudes toward campus board use, and willingness to participate in future research.

Results-Seventy-three coaches representing 3090 adolescent climbers completed the survey. Fortysix coaches $(63 \%)$ reported using full weight (no foot contact) campus board training in some or all of their climbers. A variety of factors were cited by coaches when deciding which climbers should or should not use the campus board, including physical maturity, climbing ability, and age, among others.

Conclusions-Climbing coaches in the United States disagree on the use of campus board training in adolescent climbers. Some coaches avoid using this training modality entirely, whereas others believe certain climbers can use it safely. There is lack of consensus in determining who those certain climbers are.
\end{abstract}

Keywords: rock climbing, sport climbing, campus board, finger stress fracture, growth plate injury

\section{Introduction}

Rock climbing is a popular sport around the world with notable growth among adolescents. ${ }^{1}$ Approximately 5 million athletes under the age of $18 \mathrm{y}$ participate in rock

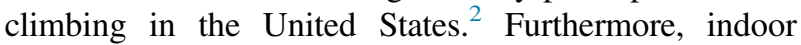
competitive climbing, or sport climbing, is becoming increasingly popular, evidenced by its addition to the 2020 Olympic Games, ${ }^{3}$ now set to debut in 2021.

Sport climbing is not without risk. Acutely, it is not uncommon to see injuries such as fractures, sprains, pulley ruptures, and ligamentous injuries. ${ }^{4,5}$ The incidence of chronic climbing injuries is more difficult to ascertain, but overuse injuries occur commonly. These injuries generally involve the upper extremity and include muscle injuries, tendinopathies, and stress fractures. ${ }^{5,6}$ Most climbing injury

Corresponding author: Christopher W. McMullen, MD, University of Washington, 325 Ninth Avenue, Box 359612, Seattle, WA 98104; e-mail: chrism86@uw.edu.

Submitted for publication July 2020.

Accepted for publication February 2021. research to date has focused on adults. As youth participation grows, knowledge of injuries and risk factors specific to the adolescent population is critically needed. One of the most consequential injuries unique to the adolescent climber is an epiphyseal stress fracture of the proximal interphalangeal (PIP) joint of the finger. ${ }^{7,8}$ The injury can occur after a clear, sudden event or insidiously, and climbers typically describe pain located at the dorsal PIP joint with point tenderness. ${ }^{9-11}$ Left untreated, this injury can result in long-term disability, deformity, and pain. ${ }^{6,9}$ The true incidence of stress fractures in the fingers of adolescent climbers is unknown owing to a scarcity of research investigating the subject. An estimated 100 cases have been reported in the literature. ${ }^{9}$ Type and quantity of training are likely critical factors in the development of this injury, yet specific training recommendations to guide climbers, climbing organizations, parents of climbers, and climbing coaches are essentially nonexistent.

Campus board training, or campusing, is a commonly used training modality among climbers. A traditional campus board consists of a series of thin wooden slats in 
a ladder-like configuration, generally secured with a slight overhang of 0 to 20 degrees off vertical (Figure 1). Campusing typically involves ascending and descending these holds without foot contact. Campus board training in adolescent climbers is controversial. Evidence, albeit limited, suggests campusing may lead to the development of finger epiphyseal stress fractures and may even result in the development of finger osteoarthritis. ${ }^{6,9,10}$ Although many athletes and coaches see it as a useful and safe training modality when used correctly, some clinicians and climbing organizations advise entirely avoiding use in athletes aged $18 \mathrm{y}$ and younger. ${ }^{5,8,9}$

A recent study assessed adolescent climbers' knowledge of safe training practices, and slightly more than half (51\%) of the 267 climbers involved were previously uninformed about growth plate injuries. ${ }^{8}$ Among this group, almost two-thirds performed potentially unsafe training practices, including campus board training. Climbing coaches likely play a vital role in guiding training practices in this population, but studies assessing coaches' practices and attitudes toward this type of training are lacking. It is unclear from the current literature whether adolescent climbing coaches believe that campus board training is a safe or useful training modality, nor is it clear whether coaches have a protocol for deciding who should or should not campus. The purpose of the present study was to investigate coaches' attitudes toward campus board training in the United States.

\section{Methods}

This study was approved by the University of Washington institutional review board. Climbing gyms were identified across the United States using Google Maps with the search term "climbing gym" state by state. Gym websites and contact information were logged in a spreadsheet. The gym's website was then used to determine whether the gym likely had an affiliated youth climbing team. Whenever listed, a direct email contact for the climbing coach was documented. All other climbing gyms with a publicized climbing team were contacted via email requesting a direct email contact for the climbing coach. For gyms that did not respond, a follow-up email was sent 1 wk later. A final request was sent to gyms 1 mo after the initial email. In this manner, a list of climbing coaches' direct emails was compiled. In cases in which multiple coaches managed the same team, the head coach or most senior coach was identified as the primary contact.

Research electronic data capture (REDCap) software tools hosted at the University of Washington were used to create the survey and collect and manage responses. REDCap is a secure, web-based software platform designed to support data capture for research studies. ${ }^{12,13}$ The survey design was edited and condensed in several phases with input from a local climbing coach, a physician and parent of an adolescent climber, and several independent musculoskeletal researchers before the creation of the final survey.

Survey questions were designed to assess the following: amount of time climbers spend training, coaches' attitudes toward campus board participation, and interest in future research participation. Questions were divided into 4 main categories: team information, training time, campus board training, and general monitoring. No questions asked for personal or team identifiers; however, respondents were asked how many climbers they personally coach to help ensure that they were in fact a team coach. Specific credentials required to be a climbing coach are established by the individual gyms at which the coaches work. Although USA Climbing does offer a coach membership and certification, this was not an explicit requirement for our survey respondents. Depending on the question, respondents were allowed to enter an integer, select 1 or many from a list of multiple choices, or answer with free text. When assessing the importance of certain factors coaches use to assess climbers' readiness for campus board training, a sliding scale was used with values of 0 to 100 ( 0 being "not something I care about" and 100 being "the most important factor I consider").

The survey was distributed to the aforementioned list of climbing coaches via email through the REDCap system. Links generated were unique to each survey recipient and could not be forwarded. Surveys were only sent to 1 coach per team in cases in which multiple coaches coached the same climbers. Additionally, respondents were explicitly instructed not to have multiple coaches of the same team complete the survey. Instruction was also included for the survey recipients not to complete the survey and instead to email our team directly if they were not coaches but had been mistakenly sent the survey. Survey recipients who did not complete the survey within 1 wk were sent 1 reminder email. Within the REDCap system, respondents were able to edit their survey answers until survey closure but were not allowed to submit more than 1 survey. All participants who completed the survey were entered into a lottery to win a $\$ 100$ gift card as an incentive for survey participation. Survey responses were received anonymously through the REDCap system, and the survey was closed approximately 6 wk after the initial invitation to participate.

All responses were then exported to a spreadsheet for analysis. Totals, percentages, medians with interquartile range (IQR), and distribution were calculated using Microsoft Excel 2009 software. The data collected were nonnormally distributed as determined by the Shapiro-Wilk test. Therefore, data were reported with median and IQR. 


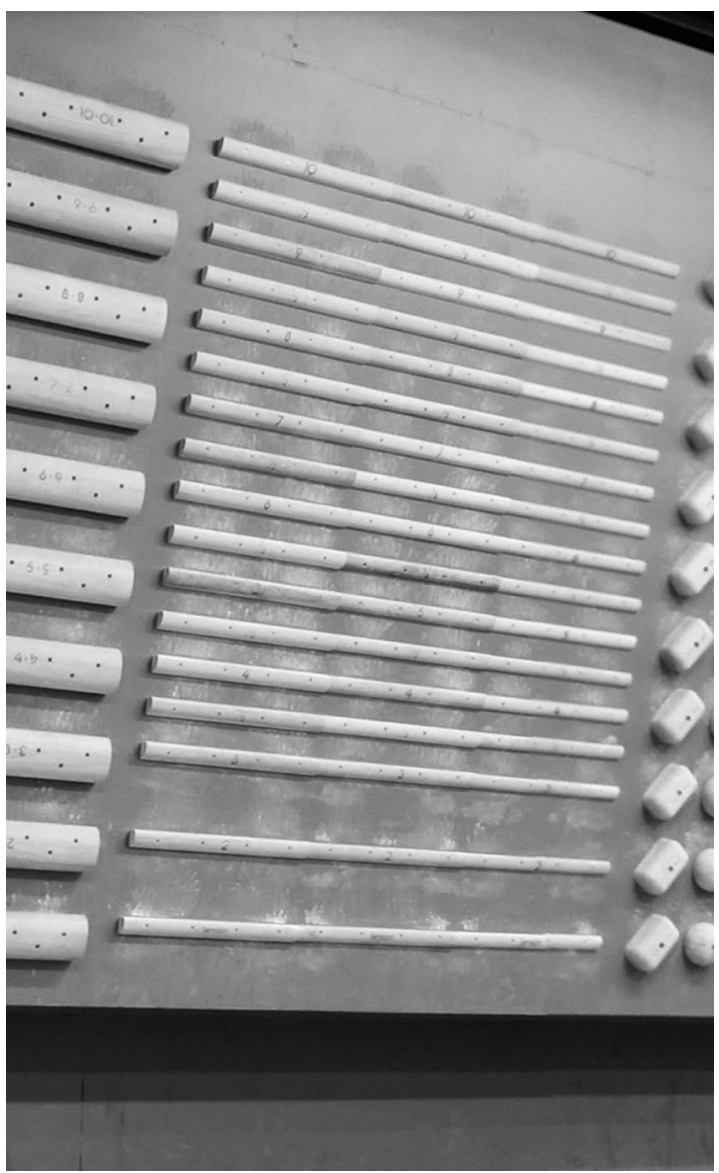

Figure 1. Traditional wooden campus board.

\section{Results}

Requests for a coach's email address were sent to 214 climbing gyms. A list of 116 coaches' email addresses was created from the gyms that responded. Seventy-three of these 116 coaches completed the survey, for a response rate of $63 \%$. Thirty-one states were represented in survey responses. A complete list of survey questions and responses is shown in Table 1.

\section{TEAM INFORMATION}

The median age of climber coached was 12 y (IQR 12-13 $\mathrm{y}$ ), with the youngest climber coached reported as $4 \mathrm{y}$ old. The number of climbers coached ranged from 5 to 160 with a median of 30 climbers per coach. The total number of climbers represented by coaches in this study was 3090 .

\section{TRAINING TIME}

For their most competitive climbers during peak training/ competition season, the respondent coaches reported that their climbers train for a median of $12 \mathrm{~h} \cdot \mathrm{wk}^{-1}(\mathrm{IQR} 10-15$ $\mathrm{h} \cdot \mathrm{wk}^{-1}$ ), with responses ranging from 5 to $25 \mathrm{~h} \cdot \mathrm{wk}^{-1}$. Coaches reported that these climbers train most of the year, with 33 of $73(45 \%)$ reporting their most competitive climbers train all 12 mo. Seven coaches $(10 \%)$ reported these climbers train $8 \mathrm{mo} \cdot \mathrm{y}^{-1}$ or less.

\section{Campus Board Training}

Forty-six coaches (63\%) reported using full-weight (no foot contact) campus board training in some or all of their climbers. In their most competitive climbers, the number of weeks per year campusing is used varied substantially, ranging from 2 to $50 \mathrm{wk} \cdot \mathrm{y}^{-1}$. Of the remaining 27 coaches who reported they do not use campus board training in their climbers, $19(70 \%)$ cited a concern that it could lead to injury.

A variety of training techniques, defined in Table 2, were used with the campus board. Half of the coaches reported other techniques in addition to those listed in the table. Many coaches reported using "bumping," a technique in which one hand remains on the bottom rung as the other hand is advanced sequentially, or "bumped," up the other rungs.

In general, coaches believed that age, climbing experience, climbing ability, the climber's comfort, and the coach's personal intuition are important factors when considering which climbers should use the campus board. Forty-two of 46 coaches who use campus board training responded in short-answer format to a question asking the coach to describe specific policies regarding campus board use in detail. Several themes emerged from these comments.

\section{PHYSICAL MATURITY}

Fifteen coaches referenced physical maturity as a measure used to evaluate readiness for campus use. Several coaches commented that a climber should be "past puberty" or "physically mature" as a prerequisite. One coach reported monitoring and recording growth rates in climbers. Another cited using x-ray and medical professional assurance that finger growth plates have indeed closed before allowing campusing.

\section{CLIMBING FORM}

Thirteen coaches referenced climbing or hanging form as a critical factor when evaluating a climber for campus use. One coach mentioned that climbers should keep shoulders "back and down" while also maintaining good body awareness. Another cited shoulder and scapular engagement as being important.

\section{TYPES OF CAMPUS BOARD HOLDS}

Nine coaches made some reference to the types of holds allowed while campusing. Some reported using only sloper 
Table 1. Complete survey questions and answers

\begin{tabular}{|c|c|c|c|}
\hline Questions and answer choices & Respondents (\%) & Median $(I Q R)$ & Range \\
\hline \multicolumn{4}{|l|}{ Team demographics } \\
\hline How old is the youngest climber you coach? & $73(100)$ & $8(7-9)$ & $4-12$ \\
\hline What is the average age of youth climbers you coach (approximately)? & $73(100)$ & $12(12-13)$ & $8-15$ \\
\hline How many youth climbers do you coach (approximately)? & $73(100)$ & $30(18-60)$ & $5-160$ \\
\hline \multicolumn{4}{|l|}{ Training } \\
\hline $\begin{array}{l}\text { During peak training or competition season, about how many hours of } \\
\text { formal (supervised) practice per week do your most competitive } \\
\text { climbers perform? }\end{array}$ & $73(100)$ & $7(6-9)$ & $4-12$ \\
\hline $\begin{array}{l}\text { During peak training or competition season, about how many hours of } \\
\text { informal (not supervised, on their own time) practice/training per week } \\
\text { do your most competitive climbers perform? }\end{array}$ & $73(100)$ & $4(3-6)$ & $0-13$ \\
\hline Total training calculated by adding 2 previous fields & & $12(10-15)$ & $5-25$ \\
\hline $\begin{array}{l}\text { During peak training or competition season, about how many hours per } \\
\text { week are your most competitive climbers literally on the wall or } \\
\text { hanging? }\end{array}$ & $73(100)$ & $5(2-6)$ & $1-12$ \\
\hline $\begin{array}{l}\text { How many months out of the year are your most competitive climbers } \\
\text { climbing? }\end{array}$ & $73(100)$ & $11(10-12)$ & $6-12$ \\
\hline $\begin{array}{l}\text { Approximately what percentage of your climbers participate } \\
\text { competitively in a sport other than climbing? }\end{array}$ & $73(100)$ & $30(11-50)$ & $0-100$ \\
\hline \multicolumn{4}{|l|}{ Campus board training } \\
\hline \multicolumn{4}{|l|}{$\begin{array}{l}\text { Do you utilize full-weight (no foot contact) campus board training with } \\
\text { your climbers? }\end{array}$} \\
\hline Yes, for all climbers & $1(1)$ & & \\
\hline Yes, for some climbers & $45(62)$ & & \\
\hline No & $27(37)$ & & \\
\hline $\begin{array}{l}\text { How many weeks out of the year do you utilize campus board training } \\
\text { in your most competitive climbers? }\end{array}$ & $46(100)$ & $10(6-20)$ & $2-50$ \\
\hline $\begin{array}{l}\text { During peak training or competition season, how many hours per week } \\
\text { do you utilize campus board training in your most competitive } \\
\text { climbers? }\end{array}$ & $46(100)$ & $1(1-1)$ & $0-2$ \\
\hline $\begin{array}{l}\text { What types of campus board training do you advise in your most } \\
\text { competitive climbers? (select all that apply) }\end{array}$ & $46(100)$ & & \\
\hline Laddering & $45(98)$ & & \\
\hline Skip laddering & $37(80)$ & & \\
\hline Switch hands & $16(35)$ & & \\
\hline Double dyno & $19(41)$ & & \\
\hline Other & $23(50)$ & & \\
\hline \multicolumn{4}{|l|}{$\begin{array}{l}\text { For the following questions a sliding scale was used. }(0=\text { "not } \\
\text { something I care about." } 50=\text { "a moderately important factor." } \\
100=\text { "the most important factor I consider.") }\end{array}$} \\
\hline When determining who should train on the campus board, age is & $46(100)$ & $79(69-98)$ & $40-100$ \\
\hline $\begin{array}{l}\text { When determining who should train on the campus board, climbing } \\
\text { experience is }\end{array}$ & $46(100)$ & $84(72-96)$ & $35-100$ \\
\hline $\begin{array}{l}\text { When determining who should train on the campus board, climbing } \\
\text { ability is }\end{array}$ & $46(100)$ & $80(71-93)$ & $49-100$ \\
\hline $\begin{array}{l}\text { When determining who should train on the campus board, the climber's } \\
\text { comfort level is }\end{array}$ & $46(100)$ & $70(55-95)$ & $31-100$ \\
\hline When determining who should train on the campus board, my intuition is & $46(100)$ & $68(50-87)$ & $9-100$ \\
\hline $\begin{array}{l}\text { How do you determine which of your climbers will utilize campus } \\
\text { board training? Do you have any concrete rules? Please be as specific } \\
\text { as possible. }\end{array}$ & $42(91)$ & & \\
\hline $\begin{array}{l}\text { If you do not utilize campus board training for some or all of your } \\
\text { climbers, why not? (select all that apply) }\end{array}$ & $72(100)$ & & \\
\hline It is not readily available & $0(0)$ & & \\
\hline
\end{tabular}


Table 1 (continued)

\begin{tabular}{|c|c|c|c|}
\hline Questions and answer choices & Respondents (\%) & Median $(I Q R)$ & Range \\
\hline I do not think it is an effective training modality & $11(15)$ & & \\
\hline I am concerned it could lead to injury & $56(78)$ & & \\
\hline $\begin{array}{l}\text { It takes time and focus away from other more important aspects of } \\
\text { training }\end{array}$ & $36(50)$ & & \\
\hline My climbers are physically unable to utilize a campus board & $31(43)$ & & \\
\hline Other & $11(15)$ & & \\
\hline $\begin{array}{l}\text { You indicated that you have a concern campus board training could } \\
\text { lead to injury. What led to this concern? }\end{array}$ & $56(100)$ & & \\
\hline Intuition (doesn't feel right) & $12(21)$ & & \\
\hline Personally experienced an injury this way & $8(14)$ & & \\
\hline Seen or coached climbers injured this way & $26(46)$ & & \\
\hline Physician or nurse's advice & $6(11)$ & & \\
\hline Physical therapist or athletic trainer's advice & $23(41)$ & & \\
\hline Scientific journal article & $24(43)$ & & \\
\hline Book, magazine, website, or news article & $33(59)$ & & \\
\hline Other & $10(18)$ & & \\
\hline $\begin{array}{l}\text { If you would like to make any additional comments or clarify any of your } \\
\text { answers regarding campus board training, please do so here: }\end{array}$ & $29(40)$ & & \\
\hline \multicolumn{4}{|l|}{ General Monitoring } \\
\hline Do you keep a record of injuries that occur with your climbers? & $73(100)$ & & \\
\hline Yes & $44(60)$ & & \\
\hline No & $29(40)$ & & \\
\hline $\begin{array}{l}\text { Would you be willing to utilize an online injury recording system to } \\
\text { track injuries in your climbers for research purposes? (climber personal } \\
\text { information would remain anonymous except to you, the coach) }\end{array}$ & $73(100)$ & & \\
\hline Yes, happily & $24(33)$ & & \\
\hline Yes, if it's easy & $40(55)$ & & \\
\hline No & $9(12)$ & & \\
\hline You answered "No." Why not? & $7(78)$ & & \\
\hline
\end{tabular}

Categorical variables are presented as $\mathrm{n}(\%)$. Continuous variables are presented as medians (interquartile ranges). Ranges are presented as minimum-maximum value. This survey used nested questions such that additional questions would appear to the survey taker only if applicable; thus, not every respondent saw every question. Percentages are based on the total number of respondents who were given that particular question.

or jug holds in younger climbers. One coach noted that only certain climbers could campus using a 30 mm edge or lower.

\section{STRENGTH/ABILITY}

Several coaches referenced specific strength targets they set for climbers before allowing campus use. For example, 1 coach noted that campus climbers should be able to perform 5 unassisted pullups. Five coaches cited that they require their climbers to boulder at least V5, an intermediate difficulty as measured by the $\mathrm{V}$-scale, a grading scale used by climbers and climbing organizations to measure the difficulty of a bouldering problem.

\section{AGE}

Seven coaches noted they have a specific minimum age cutoff for campus board training. One coach cited using age $14 \mathrm{y}$ as a cutoff, 1 coach cited age $15 \mathrm{y}, 3$ coaches cited age $16 \mathrm{y}$, and 1 coach cited age $17 \mathrm{y}$.

\section{GENERAL MONITORING}

A majority of coaches (60\%) reported keeping a record of injuries in their climbers. Sixty-four $(88 \%)$ expressed a willingness to use a central database to record injuries if it were available. Those who expressed they would be unwilling cited a lack of time to do so and/or concern about parental permission and anonymity.

\section{Discussion}

There is a paucity of published data regarding training habits among competitive adolescent climbers. The purpose of the present study was to investigate coaches' attitudes toward campus board training in the United States. We received survey responses from 73 coaches, representing over 3000 climbers. These responses provide insight into current training practices among adolescent climbing teams in the United States and warrant further investigation. 
Table 2. Definitions of campus board training modalities

\begin{tabular}{ll}
\hline Training modality & Definition \\
\hline Laddering & Ascending hand-over-hand to the top of the board \\
$\begin{array}{l}\text { Skip laddering } \\
\text { Switch hands }\end{array}$ & $\begin{array}{l}\text { Ascending hand-over-hand, skipping every other rung or more, to the top of the board } \\
\text { One hand positioned on 1 rung, the other positioned 1 rung higher, followed by switching hands mid-air } \\
\text { simultaneously to the opposite rungs, and repeating }\end{array}$ \\
$\begin{array}{l}\text { Double dyno } \\
\text { Simultaneously removing both hands from } 1 \text { rung and moving to the next rung or higher and then either } \\
\text { dropping back to the original rung simultaneously with both hands and repeating or ascending until } \\
\text { reaching the top of the board }\end{array}$ \\
\hline
\end{tabular}

\section{TRAINING TIME}

According to survey responses, nearly half of coaches' most competitive climbers train year-round. The American Orthopaedic Society for Sports Medicine recommends that athletes play a single sport no more than 8 $\mathrm{mo} \cdot \mathrm{y}^{-1} \cdot{ }^{14}$ Ninety percent of coaches in the present study estimated their most competitive climbers are climbing more than this. Consequences of overtraining have been documented in numerous sports and include overuse injuries, extremity pain, and burnout. ${ }^{15-17}$ The present study was not specifically designed to assess for overtraining among climbers, but findings indicate a need for future studies that prospectively quantify how much time this cohort spends training.

\section{CAMPUS BOARD TRAINING}

More than half of coaches surveyed use full-weight (no foot contact) campus board training in some or all of their climbers. There are several potential mechanisms by which this type of training might put adolescent climbers at risk of developing epiphyseal stress fractures in the fingers. First, the thin ledge of a campus board generally necessitates the use of a crimp grip (Figure 2). This grip results in stress directed to the PIP joints, especially in the ring and middle fingers. ${ }^{10,18}$ In adolescent climbers, it is thought that those forces can lead to fracture either acutely or with repetitive stress. ${ }^{5,9,10}$ Salter-Harris type 3 fractures are seen most commonly, potentially because forceful flexion of the PIP joint during a crimp grip pushes the epiphysis dorsally and compresses it. ${ }^{10,19}$ Another mechanism by which campusing may lead to injury is via the double dyno manuever. ${ }^{5,6,10,20}$ A double dyno involves simultaneously removing both hands from one rung and jumping to the next rung or higher without use of the feet. This is often performed repetitively on the campus board. In the present study, $26 \%$ of coaches recommend double dyno training for at least some of their climbers.

A recent study suggests that speed climbing may be a risk factor for the development of growth plate injuries of the fingers as well. ${ }^{20}$ Speed climbing is a climbing discipline that involves ascending a wall with uniform holds and hold placements as fast as possible. Campusing and speed climbing are similar in that they often involve repetitive dynamic movements such as the double dyno maneuver. ${ }^{20}$ Because these maneuvers are done without foot contact, force through the upper extremities must overcome the climber's entire body weight. Repetitious force on the fingers could conceivably lead to growth plate fractures.

Lastly, adolescent climbers may be particularly vulnerable to growth plate injuries during growth spurts as bony maturation lags increasing musculotendinous use and force generation. ${ }^{21} \mathrm{~A}$ combination of factors likely play a role in the development of this injury.

The majority of coaches surveyed believed campus board training to be an appropriate training modality for selected individuals. Approximately three-quarters of coaches expressed concern over the potential risk of injury and therefore exert some degree of caution. However, there was a lack of consensus regarding what restrictions should be in place and for whom. Twenty-one percent of coaches specifically referenced physical maturity as a prerequisite for campus use. This aligns with evidence suggesting athletes are particularly susceptible to epiphyseal injury during growth spurts., ${ }^{9,10,21}$ However, it is unclear how coaches are measuring physical maturity. One coach reported monitoring growth curves. Another reported obtaining x-rays to confirm growth plate closure. Although x-rays can indeed confirm growth plate closure, ${ }^{22}$ this exposes the athlete to radiation that may be unwarranted. Ten percent of coaches reported a strict minimum age required for campus board use. However, if the goal is to wait for growth plate closure, an age cutoff of at least $17 \mathrm{y}$ is probably required. ${ }^{9}$ This contradicts climbers' beliefs concerning campus board training - a majority believe it is safe to start double dyno campusing younger than age $18 \mathrm{y} .{ }^{8}$ Eighteen percent of coaches specifically referenced an attention to climbing or hanging form as being critical to determining who should be allowed to campus. Often, they mentioned shoulder and scapular engagement as 

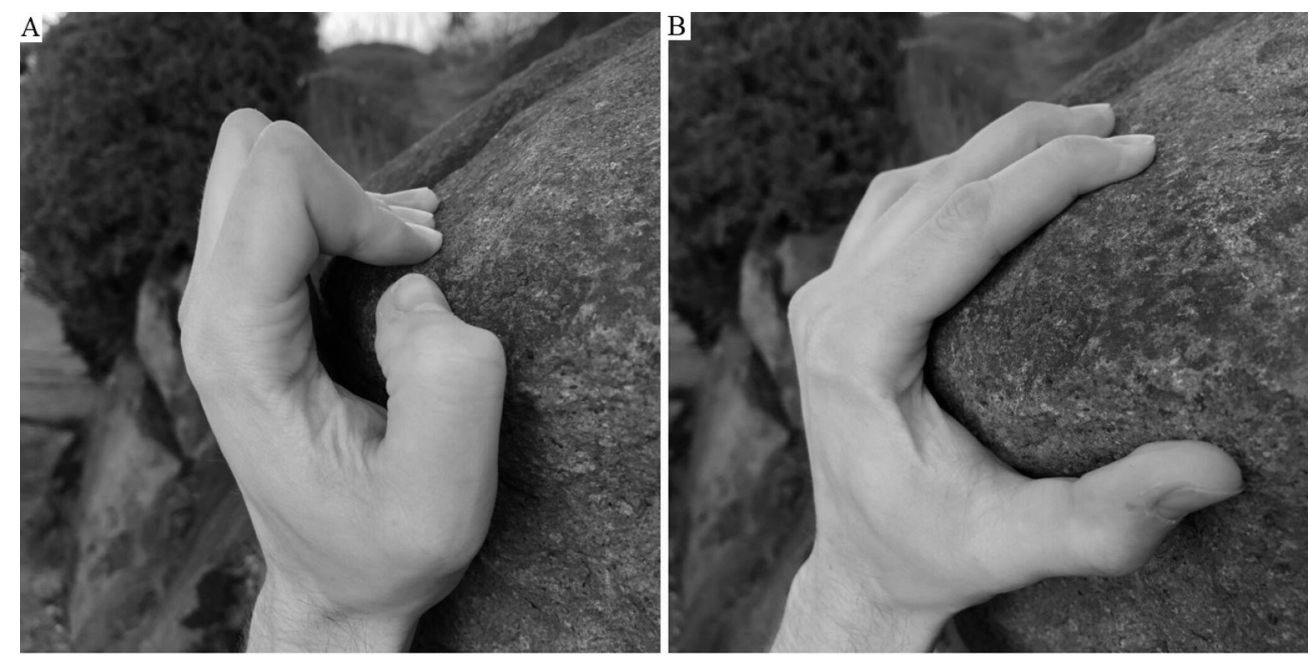

Figure 2. (A) Crimp grip. (B) Open hand grip.

being critical. Strength and proper activation of the shoulder and periscapular stabilizers might decrease load through the finger flexors during dynamic movements, but this is unproven and requires further investigation. As discussed, an open grip exerts less stress through the PIP joints than a crimp grip (Figure 2) ${ }^{11} \mathrm{~A}$ traditional campus board consists of wooden slats; however, boards can be modified, and larger jug or sloper holds could be used as an alternative to thin ledges. These types of holds are more likely to encourage an open hand grip. Twelve percent of coaches made specific reference to the types of holds used in their training regimens, generally commenting that they promote larger holds in younger or less experienced athletes.

Overall, many coaches using the campus board with their athletes claim to do so in a thoughtful manner; however, prospective studies are needed to help determine the type and quantity of campus board use that is appropriate in this cohort.

\section{LIMITATIONS}

Our study is limited by its design as a survey and may suffer from recall bias. Our findings, particularly surrounding training time, should be interpreted with caution. Questions regarding how much climbers train relied on 1 group, coaches, recalling activity on the part of a second group, climbers. Although coaches may have been able to provide a reasonably accurate account of training time they formally supervised, they may have been unable to reliably estimate time spent training outside of supervised practice. This indirect assessment of training time decreases the overall reliability of the data. Additionally, many questions in our survey asked coaches for approximations or averages. These terms may have been interpreted differently among respondents. Coaches were asked to estimate how much their most competitive climbers train. "Most competitive" is subjective, and some coaches may have included more climbers than others when considering this term. Answers may have differed had we asked coaches to recall information regarding their "average climber." Coaches may have differing opinions of what defines campus board training, and that may have affected their response.

A novel survey was used for this study. A random sample was not compared to the overall sample, and this may reduce generalizability.

Coaches' responses potentially suffered from selection bias. Coaches in this study were identified by the climbing gyms for which they work and the teams they coach. They were not required to be formally credentialled or provide proof of license. Efforts were made to contact as many US climbing gyms as possible to create a comprehensive list of climbing coaches, but it is possible that some gyms were missed and never contacted and that some coaches work independently of climbing gyms. Additionally, it may be that those coaches more willing to participate in a survey are more likely to be interested in climbing research and more likely to consider how training may relate to injury.

\section{Conclusions}

Climbing coaches in the United States disagree on the use of campus board training in adolescent climbers. Some coaches avoid using this training modality entirely whereas others believe certain climbers can use it safely. 
There is lack of consensus in determining who those certain climbers are. Physical maturity, age, ability level, and climbing form were cited as key factors, but specific criteria varied. This likely stems in part from a lack of evidence-based consensus guidelines in the United States and underscores the opportunity for further research. Coaches can play a helpful role in this endeavor and should continue to be recruited for future studies. We feel an obligation to help develop and substantiate training guidelines to protect the adolescent climbing community, and we enthusiastically welcome others into this effort.

Acknowledgments: We acknowledge Audrey Young, MD, for her assistance in reviewing and providing feedback during the creation of our survey and the University of Washington Clinical Learning, Evidence and Research (CLEAR) Center for Musculoskeletal Disorders for assistance in developing our study design.

Author Contributions: Study concept and design (CM, BM); acquisition of the data (CM, BM); analysis of the data (CM, BM, LB); drafting of the manuscript (CM, LB); critical revision of the manuscript (CM, BM, LB); and approval of final manuscript (CM, BM, LB).

Financial/Material Support: None.

Disclosures: None.

\section{References}

1. Woollings KY, McKay CD, Emery CA. Risk factors for injury in sport climbing and bouldering: a systematic review of the literature. Br J Sports Med. 2015;49(17):1094-9.

2. Siegel SR, Fryer SM. Rock climbing for promoting physical activity in youth. Am J Lifestyle Med. 2015;11(3):243-51.

3. Lutter C, El-Sheikh Y, Schoffl I, Schoffl V. Sport climbing: medical considerations for this new Olympic discipline. $\mathrm{Br}$ J Sports Med. 2017;51(1):2-3.

4. Buzzacott P, Schoffl I, Chimiak J, Schoffl V. Rock climbing injuries treated in US emergency departments, 2008-2016. Wilderness Environ Med. 2019;30(2):121-8.

5. Schoffl V, Popp D, Kupper T, Schoffl I. Injury trends in rock climbers: evaluation of a case series of 911 injuries between 2009 and 2012. Wilderness Environ Med. 2015;26(1):62-7.

6. Schoffl VR, Hoffmann PM, Imhoff A, Kupper T, Schoffl I, Hochholzer T, et al. Long-term radiographic adaptations to stress of high-level and recreational rock climbing in former adolescent athletes: an 11-year prospective longitudinal study. Orthop J Sports Med. 2018;6(9):2325967118792847.

7. Hochholzer T, Schoffl VR. Epiphyseal fractures of the finger middle joints in young sport climbers. Wilderness Environ Med. 2005;16(3):139-42.

8. Meyers RN, Hobbs SL, Howell DR, Provance AJ. Are adolescent climbers aware of the most common youth climbing injury and safe training practices? Int J Environ Res Public Health. 2020;17(3):812.
9. Bartschi N, Scheibler A, Schweizer A. Symptomatic epiphyseal sprains and stress fractures of the finger phalanges in adolescent sport climbers. Hand Surg Rehabil. 2019;38(4):251-6.

10. Schoffl I, Schoffl V. Epiphyseal stress fractures in the fingers of adolescents: biomechanics, pathomechanism, and risk factors. Eur J Sport Med. 2015;3(1):11.

11. Desaldeleer AS, Le Nen D. Bilateral fracture of the base of the middle phalanx in a climber: literature review and a case report. Orthop Traumatol Surg Res. 2016;102(3):409-11.

12. Harris PA, Taylor R, Thielke R, Payne J, Gonzalez N, Conde JG. Research electronic data capture (REDCap)-a metadata-driven methodology and workflow process for providing translational research informatics support. J Biomed Inform. 2009;42(2):377-81.

13. Harris PA, Taylor R, Minor BL, Elliott V, Fernandez M, O'Neal L, et al. The REDCap consortium: building an international community of software platform partners. J Biomed Inform. 2019;95:103208.

14. LaPrade RF, Agel J, Baker J, Brenner JS, Cordasco FA, Cote J, et al. AOSSM early sport specialization consensus statement. Orthop J Sports Med. 2016;4(4):2325967116644241.

15. Brenner JS. Overuse injuries, overtraining, and burnout in child and adolescent athletes. Pediatrics. 2007;119(6):1242-5.

16. DiFiori JP, Benjamin HJ, Brenner J, Gregory A, Jayanthi N, Landry GL, et al. Overuse injuries and burnout in youth sports: a position statement from the American Medical Society for Sports Medicine. Clin J Sport Med. 2014;24(1):3-20.

17. Jayanthi NA, Post EG, Laury TC, Fabricant PD. Health consequences of youth sport specialization. J Athl Train. 2019;54(10):1040-9.

18. Vigouroux L, Quaine F, Paclet F, Colloud F, Moutet F. Middle and ring fingers are more exposed to pulley rupture than index and little during sport-climbing: a biomechanical explanation. Clin Biomech (Bristol, Avon). 2008;23(5):562-70.

19. Bayer T, Schoffl VR, Lenhart M, Herold T. Epiphyseal stress fractures of finger phalanges in adolescent climbing athletes: a 3.0-Tesla magnetic resonance imaging evaluation. Skeletal Radiol. 2013;42(11):1521-5.

20. Meyers RN, Howell DR, Provance AJ. The association of finger growth plate injury history and speed climbing in youth competition climbers. Wilderness Environ Med. 2020;31(4):394-9.

21. Arnold A, Thigpen CA, Beattie PF, Kissenberth MJ, Shanley E. Overuse physeal injuries in youth athletes: risk factors, prevention, and treatment strategies. Sports Health. 2017;9(2):139-47.

22. Nguyen JC, Markhardt BK, Merrow AC, Dwek JR. Imaging of pediatric growth plate disturbances. Radiographics. 2017;37(6):1791-812. 